\title{
BACTERIOLOGICAL PROFILE OF DIABETIC FOOT INFECTIONS AND ITS EFFECTS ON LIMB SALVATION
}

\author{
Muhammad Umair Zulfiqar, Umer Fayyaz Ghani, Ayub Ashraf Mallhi*, Khalid Mahmood*, Maria Iqbal**, Muhammad Ans* \\ Pak Emirates Military Hospital/National University of Medical Sciences (NUMS) Rawalpindi Pakistan, *Combined Military Hospital/National University of \\ Medical Sciences (NUMS) Rawalpindi Pakistan, **Bahawal Victoria Hospital, Bahawalpur Pakistan
}

\begin{abstract}
Objective: To assess the bacteriological profile of infected diabetic foot and its relationship with limb salvation among the patients treated for diabetic foot infection at a tertiary setup.

Study Design: Correlational study.

Place and Duration of Study: Department of Surgery, Pak Emirates Military Hospital Rawalpindi, from Dec 2018 to Mar 2019. Methodology: A total of 160 cases of infected diabetic foot were included in the study. Diagnosis of diabetic foot was made by the consultant surgeon and bacteriological analysis was done on the specimen by the microbiology laboratory of the same hospital. Relationship of bacteriological profile and other socio-demographic factors was assessed with limb salvation in these patients.

Results: There were 121 (75.6\%) male patients while females were 39 (24.4\%). Commonest organism found was Staphylococcus aureus $49(30.6 \%)$ which was followed by pseudomonas $39(24.4 \%)$. Out of 160 patients treated for the diabetic foot infection, 71 $(48.4 \%)$ had to undergo the process of limb salvation while 89 (51.6\%) were managed conservatively. Poly-microbial infection and raised body mass index (BMI) were significantly associated with limb salvation in the target populace $(p$-value $<0.05)$.

Conclusion: This study depicted high frequency of patients undergoing limb salvation due to diabetic foot infections in our setup. Patients with raised body mass index and those with poly-microbial infection on the culture should be specially attended in order to avoid this irreversible damage to the patient in the process of saving his life from the infective process.
\end{abstract}

Keyword: Diabetic foot infection, Limb salvation, SB acteriological profile.

This is an Open Access article distributed under the terms of the Creative Commons Attribution License (http://creativecommons.org/licenses/by/4.0), which permits unrestricted use, distribution, and reproduction in any medium, provided the original work is properly cited.

\section{INTRODUCTION}

Diabetes mellitus has commonly been associated with morbidity and mortality in all age groups in every part of the world ${ }^{1}$. It is disease of a medical origin; due to its devastating nature and end organ damage linked to it, involves physicians from multiple specialties including the surgery. Carbuncles, abscesses especially at unusual sites, limb ischemia secondary to increased atherosclerotic phenomenon and infected diabetic foot have been some common surgical presentations of this syndrome ${ }^{2,3}$.

Foot care has been an area of interest for the surgeons, physicians, general practitioners and public health experts among the patients of diabetes. Vascular complications with decreased immunity lead to severe infections of the feet after minor trauma ${ }^{4}$. This infective phenomenon if unchecked may lead to limb loss of the patient. Therefore accurate knowledge of pathogenesis and related risk factors is must for the surgeons in order to implement primary or secondary prevention strategies among these patients and prevent the step of amputation.

Correspondence: Dr Muhammad Umair Zulfiqar, Department of Surgery, Pak Emirates Military Hospital, Rawalpindi Pakistan

Received: 01 Feb 2020; revised received: 23 Feb 2020; accepted: 28 Feb 2020
Diabetes related complications have been a challenge for health professionals of various specialties. Major amputation of the affected limb with diabetic complications is usually the last stay of treatment but unfortunately is quite common in all parts of the world especially the developing countries ${ }^{5-7}$.

Limb salvation saves the individual from life threatening complications of diabetic foot but has a lot of negative consequences on the life of individual. Overall quality of life is affected with multiple psychological and social problems among the individuals undergoing this type of treatment ${ }^{8-10}$.

Ours is a developing country with limited resources. In a non-welfare state like ours government usually does not provide any special employment or allocate funds for the people who have permanent disability after the limb salvation. Patients sometimes are only bread earners of their families and after the disability have no option other than depending on the help from others. Therefore it is a special need for our set up to work for prevention or early recognition and aggressive treatment of this problem to avoid the prolonged misery. We planned our study with the rationale to sight the bacteriological profile of patients suffering from diabetic foot infection and their effect on limb salvation. 


\section{METHODOLOGY}

This correlational research was carried out at the surgical department of Pak Emirates Military Hospital Rawalpindi, from December 2018 to March 2019. We calculated our sample size by using WHO Sample Size Calculator by using population prevalence proportion of $85 \%{ }^{11}$. Sampling technique was non probability consecutive sampling. Our inclusion criteria consisted of patients between the age of 18-65 years suffering from diabetic foot infection either seen at OPD or hospitalized in the ward. Patients having any chronic illness other than diabetes mellitus were excluded. Patients with bleeding disorders, leukemia and lymphomas were also part of the exclusion criteria. Immuno-compromised patients with cause other than diabetes, autoimmune disorder patients and patients on long term steroids were also not included. Pregnant ladies and illicit drug users were also excluded at the first step. Patients who were not willing to send the cultures or giving informed consent for this study were also not included in the study. Limb salvation surgery was defined as the surgery which involved major amputation of the affected limb.

We sought ethics approval (letter no A/28/EC/ 56/19) from the ethics review board committee and obtained informed written consent from participants. Diabetic foot infection was assessed and diagnosed by a consultant surgeon on the basis of International Classification of Diseases, 9th revision (ICD-9) codes related to diabetic foot ulcer or diabetes-related Lower extremity amputation in diabetic patients who were admitted for diabetic foot ulcer ${ }^{10}$. Microbiology laboratory of the same hospital was used to send the cultures from affected limb and get the report of bacteriological profile for each case. Relationship of gender, age, education, smoking, duration of diabetes and presence of poly microbial infection was analyzed with the presence of limb salvation among the patients managed at PEMH RWP. A special form was created for this study which included the socio demographic profile and all the possible classes of bacteria which have been involved in the diabetic foot infections. Education was classed as less than matriculate or matriculate or more. Diabetes duration was grouped into greater than or less than 5 year duration.

Statistical analysis was done with the help of SPSS 24. Percentages and Frequency for gender, different classes of bacteria and patients undergoing limb salvation were recorded. Mean and standard deviation for age and duration of diabetes was also calculated for the study participants. Relationship of age, gender, education, smoking, duration of diabetes and presence of poly microbial infection was assessed with the management done via limb salvation amongst patients undergoing treatment for diabetic foot infections with the help of binary logistic regression after applying the chi-square test.

\section{RESULTS}

A total of 168 patients were able to participate in the study. Three were not ready to send the culture specimens to the laboratory. Two had a comorbid autoimmune disorder while three were using opiate substance. Therefore total 160 patients participated in the study. Mean age was $45.53 \pm 5.738$ years. There were $39(24.4 \%)$ females and $121(75.6 \%)$ patients were males. Out of 160 patients of infected diabetic foot, 71 $(44.3 \%)$ had to undergo limb salvation surgery (major amputation) as management plan while 89 (55.7\%) were managed conservatively (table-I). We applied logistic regression after the chi-square test and found

Table-I: Characteristics of study participants $(n=160)$.

\begin{tabular}{l|c}
\hline Age (Years) & \multicolumn{1}{|l}{} \\
\hline Mean \pm SD & $\begin{array}{c}\text { 25.53 } \pm 5.738 \text { years } \\
25-64 \text { years }\end{array}$ \\
Range (Min-Max) & $121(75.6 \%)$ \\
\hline Gender & $39(24.4 \%)$ \\
\hline Male & $5.69 \pm 7.431$ years \\
Female & \\
\hline Mean duration of Diabetes & $89(55.7 \%)$ \\
Mellitus & $71(44.3 \%)$ \\
\hline Management Plan & \\
\hline Conservative & $49(30.6 \%)$ \\
Limb salvation & $39(24.4 \%)$ \\
\hline Bacteriological Profile & $29(18.1 \%)$ \\
\hline Staphylococcus aureus & $27(16.8 \%)$ \\
Pseudomonas aeruginosa & $22(13.7 \%)$ \\
Escherichia coli & $11(6.8 \%)$ \\
Streptococcus epidermatitis & $10(6.2 \%)$ \\
Klebsiella pneumonia & $30(18.7 \%)$ \\
Enterococcus &
\end{tabular}

presence of poly-microbial infection on culture and high body mass index has major association with the limb salvation in patients managed for the diabetic foot infections at our tertiary care hospital during the study period (table-II).

\section{DISCUSSION}

Aggressive treatment at initial stage, if not prevention can save the patient from this lifelong misery of losing a limb as described by Macruru et al, in 2018 
Table-II: The correlated factors relating to patients undergoing limb salvation for the diabetic foot infection: the binary logistic regression analysis.

\begin{tabular}{|c|c|c|c|c|}
\hline & \multirow{2}{*}{$\begin{array}{c}p \text { - } \\
\text { value }\end{array}$} & \multirow{2}{*}{$\begin{array}{l}\text { Odds } \\
\text { Ratio }\end{array}$} & \multicolumn{2}{|c|}{$\begin{array}{l}\text { Confidence } \\
\text { Interval }\end{array}$} \\
\hline & & & Lower & Upper \\
\hline \multicolumn{5}{|l|}{ Age } \\
\hline$\geq 35$ years & 0.651 & 0.835 & 0.382 & 1.823 \\
\hline \multicolumn{5}{|c|}{ Duration of Diabetes } \\
\hline$>5$ years & 0.164 & 0.435 & 0.135 & 1.404 \\
\hline \multicolumn{5}{|l|}{ Gender } \\
\hline Male & 0.056 & 0.387 & 0.146 & 1.024 \\
\hline \multicolumn{5}{|l|}{ Education } \\
\hline$\geq$ Matriculate & 0.399 & 1.411 & 0.634 & 3.143 \\
\hline \multicolumn{5}{|l|}{ BMI } \\
\hline$>25$ & 0.001 & 14.862 & 3.056 & 72.283 \\
\hline \multicolumn{5}{|c|}{ Poly-Microbial Infection } \\
\hline $\begin{array}{l}\text { No poly-micro- } \\
\text { bial infection }\end{array}$ & 0.001 & 8.350 & 2.467 & 28.266 \\
\hline \multicolumn{5}{|l|}{ Smoking } \\
\hline No smoking & 0.222 & 2.040 & 0.650 & 6.400 \\
\hline
\end{tabular}

and Welidi et al, in 201411,12. Various studies in the past have conducted research on bacteriological profile among patients who have suffered from diabetic foot infections. Most common bacteria found in the diabetic wound was Staphylococcus aureus followed by the Enterococcus faecalisin a study done on the patients of infected diabetic foot by Jneid et al, in $2018^{13}$. A similar study done in Karachi a cosmopolitan city of our country revealed that most cases of diabetic foot infections had poly-microbial cultures including both gram negative and gram positive bacteria ${ }^{14}$. One study which was done at KSA revealed that older age and raised white cell count had a strong link with the limb salvation treatment among diabetic foot patients ${ }^{15}$.

This study is interesting in the aspect that it revolves around the serious surgical complication of a medical illness and emphasizes on liaison between different specialties for the better management of the patients. Even non clinical specialties like microbiology have a vital role in chalking out the exact management plan for the patients with infective etiologies. After the advent of newer classes of antibiotics, different forms of insulin and newer hypoglycemic agents and sophisticated methods of isolating the exact organism involved in the infective process, number of limb salvation surgeries have declined in the past decade especially among the developing countries ${ }^{17}$. Situation in third world countries has still not changed much and every year a huge number of patients have to undergo these surgeries in order to avoid further complications ${ }^{8,18}$.
We therefore planned this study to look for the frequency of limb salvation and bacteriological profile of these patients and establish a link between various risk factors and limb salvation including the type of bacteria involved.

Commonest bacteria found in our analysis were staphylococcus aureus followed by pseudomonas. Study done in 2018 in our own country by Kaimkhani et al, with similar design revealed that Escherichia coli was the commonest organism in their patients ${ }^{14}$. Poly-microbial infections were found more in our target population as compared to their patients. Study in the west by Jneid et al, in 2018 had also shown similar organism profile with slight change ${ }^{13}$. These differences can be understandable in context of difference in environment and common organisms inhabiting in these environments.

Limb amputation in our study was opted for almost $44 \%$ of the patients at one level or another. The rates of amputation were comparable with the rates generated by a study done in KSA in recent past ${ }^{15}$. This high rate reflects the poor glycemic control in the Asian countries and highlights the importance of educating the patients regarding primary and secondary prevention for this chronic illness. It also shows the negligence in the aspect of timely reaching the health care facility in order to treat the infection and glycemic control both in time to avoid the elimination surgery like limb amputation.

Our study constituted male patients in majority. Epidemiological studies previously conducted at Pakistan by Kainkhani et al, in 2018 and the west by Mariam et al, in 2017 established male predominance in patients of diabetic foot infection ${ }^{14,18}$. Relationship of gender though was insignificant with the presence of limb salvation in our sample. Predominant male sample may be due to the sampling bias as we obtained sample from a tertiary care military hospital where most entitled patients are the male soldiers and officers. It may also be the reason that females could overcome infection more resiliently so they have lesser chance of getting their limb amputated due to this reason. Further studies carried out in public sector hospital may throw more light on this phenomenon.

Poly-microbial infection emerged as an independent risk factor for the limb salvation surgery in our study population. Similar findings have been reported in the past as well by Jeong et al, in 201719. Poly-microbial infections reflect the immune-compromised status of the patient as well as raise the question of good 
combination antibiotics which can cure the infection at the cost of minimum side effects.

Raised BMI, i.e. patients who were obese or over weight were more at the risk of getting amputation of lower limb due to diabetic foot infection as compared to those with normal BMI. Literature in the past support this associarion ${ }^{20}$. As expected, high BMI not only worsens the resistance to good glycemic control even with the use of pharmacological aid but also increases the chances of getting an infection. This supports both the reasons which lead to treatment resistance of diabetic foot infection and limb salvation.

Despite its simple and clear design, there were few limitations in this study which hindered in the generalization of the results. Type of treatment of diabetes and diabetic control was not made part of the study design as prior liaison with medical department was not carried out at start of the study. These parameters can affect both the parameters of this study, bacteriological profile as well as limb salvation. All the patients of limb salvation were included despite the level of amputation. Bacteriological profile and other parameters may affect the extent of limb salvation in addition to provide a basis for this procedure. Future studies involving medical department as well and including a larger sample size may generate generalizable results in this regard.

\section{CONCLUSION}

This study depicted a high frequency of patients undergoing limb salvation due to diabetic foot infections in our setup. Patients with raised BMI and those with poly-microbial infection on the culture should seek special attention in order to avoid this irreversible damage to the patient in the process of saving his life from the infective process.

\section{CONFLICT OF INTEREST}

This study has no conflict of interest to be declared by any author.

\section{REFERENCES}

1. Papatheodorou K, Banach M, Bekiari E, Rizzo M. Complications of diabetes 2017. J Diabetes Res 2018; 20(18): 3086167-70.

2. Namba M, Iwakura T, Nishimura R, Akazawa K, Matsuhisa M, Atsumi $Y$, et al. The current status of treatment-related severe hypoglycemia in Japanese patients with diabetes mellitus: A report from the committee on a survey of severe hypoglycemia in the Japan Diabetes Society[published online ahead of print, 2018 Mar 2]. J Diabetes Investig 2018; 9(3): 642-56.

3. Papatheodorou K, Papanas N, Banach M. Complications of diabetes. J Diabetes Res 2016; 20(16): 6989453-55.

4. Mavrogenis AF, Megaloikonomos PD, Antoniadou T, Igoumenou VG, Panagopoulos GN, Dimopoulos L, et al. Current con- cepts for the evaluation and management of diabetic foot ulcers. EFORT Open Rev 2018; 3(9): 513-25.

5. Jiang Y, Ran X, Jia L, Yang C, Wang P, Ma J, et al. Epidemiology of type 2 diabetic foot problems and predictive factors for amputation in China. Int J Low Extrem Wounds 2015; 14(1): 19-27.

6. Wang DD, Jamjoom RA, Alzahrani AH, Hu FB, Alzahrani HA. Prevalence and correlates of lower-extremity amputation in patients with diabetic foot ulcer in Jeddah, Saudi Arabia. Int J Low Extrem Wounds 2016; 15(1): 26-33.

7. Xu B, Yang CZ, Wu SB, Zhang D, Wang LN, Xiao L, et al. Risk factors for lower extremity amputation in patients with diabetic foot. Zhonghua Nei Ke Za Zhi 2017; 56(1): 24-28.

8. Amoah VMK, Anokye R, Acheampong E, Dadson HR, Osei M, Nadutey A. The experiences of people with diabetes-related lower limb amputation at the KomfoAnokye Teaching Hospital (KATH) in Ghana. BMC Res Notes 2018; 11(1): 66-68.

9. Baars EC, Schrier E, Dijkstra PU, Geertzen JHB. Prosthesis satisfaction in lower limb amputees: a systematic review of associated factors and questionnaires. Med (Baltimore) 2018; 97(39): e12296-98.

10. Bhuvaneswar CG, Epstein LA, Stern TA. Reactions to amputation: recognition and treatment. Prim Care Companion J Clin Psy 2007; 9(4): 303-8.

11. Mac Rury S, Stephen K, Main F, Gorman J, Jones S, Macfarlane D. Reducing amputations in people with diabetes (RAPID): Evaluation of a New Care Pathway. Int J Environ Res Public Health 2018; 15(5): 999-02.

12. Weledji EP, Fokam P. Treatment of the diabetic foot - to amputate or not?. BMC Surg 2014; 14(2): 8385.

13. Jneid J, Cassir N, Schuldiner S, Jourdan N, Sotto A, Lavigne JP, et al. Exploring the Microbiota of Diabetic Foot Infections With Culturomics. Front Cell Infect Microbiol 2018; 8(1): 282-85.

14. Kaimkhani GM, Siddiqui AA, Rasheed N, Rajput MI, Kumar J, $\mathrm{Khan} \mathrm{MH}$, et al. Pattern of infecting microorganisms and their susceptibility to antimicrobial drugs in patients with diabetic foot infections in a tertiary care hospital in Karachi, Pakistan. Cureus 2018; 10(6): e2872-75.

15. Musa IR, Ahmed MON, Sabir EI, Alsheneber IF, Ibrahim EME, Mohamed GB, et al. Factors associated with amputation among patients with diabetic foot ulcers in a Saudi population. BMC Res Notes 2018; 11(1): 260-65.

16. Kim CH, Moon JS, Chung SM, Kong EJ, Park CH, Yoon WS, et al. The changes of trends in the diagnosis and treatment of diabetic foot ulcer over a 10-year period: single center study. Diabetes Metab J 2018; 42(4): 308-19.

17. Yazdanpanah L, Shahbazian H, Nazari I, AArt HR, Ianinejad SE, Cheraghian B. Incidence and risk factors of diabetic foot ulcer: a population-based diabetic foot cohort (ADFC Study)-two-year follow-up study. Int J Endocrinol 2018; 20(18): 7631659-62.

18. Mariam TG, Alemayehu A, Tesfaye E, Mequannt W, Temesgen $\mathrm{K}$, Yetwale F, et al. Prevalence of diabetic foot ulcer and associated factors among adult diabetic patients who attend the diabetic follow-up clinic at the university of gondar referral hospital, North West Ethiopia, 2016: Institutional-Based Cross-Sectional Study. J Diabetes Res 2017; 20(17): 2879249-52.

19. Jeong EG, Cho SS, Lee SH, Lee KM, Woo SK, Kang Y, et al. Depth and combined infection is important predictor of lower extremity amputations in hospitalized diabetic foot ulcer patients. Korean J Intern Med 2017; 33(5): 952-60.

20. Pemayun TG, Naibaho RM, Novitasari D, Amin N, Minuljo TT. Risk factors for lower extremity amputation in patients with diabetic foot ulcers: a hospital-based case-control study Diabet Foot Ankle 2015; 6(1): 29629-32. 